\title{
Elements of a Sociological Contribution to Happiness Studies:
}

Submitted to Sociology Compass

(A revised version is now forthcoming in that journal)

\section{David Bartram}

\author{
Department of Sociology \\ University of Leicester \\ University Road \\ Leicester LE1 7RH \\ United Kingdom \\ t: +44 1162522724 \\ f: +441162525259 \\ d.bartram@le.ac.uk
}

October 2011 


\section{Abstract}

A significant body of social-science research on happiness has accrued in recent decades, produced mainly by economists and psychologists. Sociologists, however, have made more limited contributions to "happiness studies". This paper provides an overview of concepts, methods and findings and suggests some questions about happiness that ought to be of substantial interest to sociology. Many sociologists are clearly interested in the well-being of the people they study (sometimes suggesting "policy implications" emerging from their empirical findings); happiness is a presumptively important form of well-being, and an engagement with happiness studies might constitute a way to develop more systematic connections between well-being and academic research. Building on existing findings, sociologists would be well-placed to consider the social context of happiness (as against an individualist orientation more common in other disciplines) as well as the unintended consequences of policy initiatives and happiness discourses. 
A great deal of sociological research is manifestly motivated by concern for the well-being of the people being researched. Many who write about citizenship, for example, are likely animated by the notion that exclusion from citizenship is detrimental to well-being: when immigrants (and their children) are restricted to extended periods of "denizenship" or worse, their lack of certain political rights matters in part because having those rights is important for well-being. One could trace similar motivations even in more abstract theoretical work: risk and vulnerability, for example, matter at least in part because of what they might mean for people's well-being.

Even so, the concern scholars have for people's well-being and its connection to the specific topic of one's research are usually not articulated explicitly in their academic writing. Granted, it is often difficult enough to fit one's empirical analysis into an 8000-word article. Some sociologists, recalling early encounters with Weber (1949 [1904]), might also be wary of mixing "facts" and "values"; direct discussions of well-being quickly take on a normative character. But avoiding a direct engagement might weaken our ability to influence the public discourses that affect policy outcomes and other processes that actually determine wellbeing. At the very least, avoidance and/or relying on "common sense" likely means that our ideas about well-being are not nearly as systematic and developed as they could be.

This article provides an overview of research in "happiness studies" and suggests that this interdisciplinary field can offer a path towards developing a more systematic understanding of well-being and its role in sociological research. Sociologists have been slower and more reluctant to embrace happiness studies than scholars in other fields (though there are some notable exceptions, particularly Ruut Veenhoven, e.g. 2008). In certain 
respects this reluctance is reasonable: there are good reasons to be sceptical of the ways happiness is sometimes conceptualized and measured, and it is not difficult to find some simplistic thinking about how research findings might be used. But these concerns are better treated as reasons to engage with the field rather than to shun it; indeed sociologists might be well placed to redress certain shortcomings in happiness research.

\section{Concept and Measurement}

To locate happiness as a research topic, we can begin with a distinction between objective and subjective well-being, where the latter is well-being that we experience and are conscious of experiencing. Happiness is the affective component of subjective well-being, while "life satisfaction" is the cognitive component, the evaluations we make about how well our lives are going. Examples of objective forms of well-being include income and other economic "goods", political rights and freedoms, social relationships and health (a list far from complete). These are "objective" insofar as they are (at least arguably) desirable even if some individuals don't recognize them as such, and perhaps desirable regardless of their subjective consequences. But subjective consequences (e.g. happiness) are important in their own right, and the reason to insist on this basic distinction between two types of well-being is that (as against the "revealed preferences" axiom of neo-classical economics) there is often not a strong correlation between them: a high level of objective well-being is no guarantee of happiness or satisfaction.

How, then, to define happiness itself? Perhaps to an even greater extent than with other sociological concepts, defining happiness is challenging in part because its meaning in everyday usage seems so obvious. Everyday usage should of course guide and inform 
scholarly treatment, but good conceptualization can help overcome certain ambiguities common to informal discussions. For example, some people believe that happiness is equivalent to pleasure (or the experience of pleasure) - but few if any happiness researchers would find value in a purely hedonic definition of happiness.

For certain purposes, it is sufficient to define happiness as "feeling good - enjoying life and wanting that feeling to be maintained" (Layard 2005, 12). That definition captures the affective core of happiness in a way that connects well with people's lived experience. There is, naturally, no shortage of more complex and elaborate definitions. The most compelling of these is from Haybron (2008), who defines happiness as a "positive emotional state" (and develops the definition over several chapters). This definition conveys a more durable quality than "feeling good": happiness comprises positive moods and emotions, but it includes "mood propensities" as well. A happy person on this account is one who finds it (relatively) easy to experience positive moods and emotions, one whose experience of life amounts to "psychic affirmation".

Measurement of happiness is a more contentious issue. A great many researchers use data from surveys (e.g. the World Values Survey) where respondents are asked to indicate their happiness on a scale that might consist of three or four or eleven points. The question itself does not include a definition; the assumption (surely a reasonable one) is that people know for themselves what happiness is and indeed that it would be undesirable to impose a researcher's definition. Since definitions and understandings can vary across cultures and countries, omitting a definition can also enhance possibilities of using survey data for crossnational comparative research (Graham 2009). Diener and Suh ask whether subjective well- 
being measures produce data that can be considered comparable across societies and conclude that "most extant evidence on this issue is encouraging" $(2003,5)$ - a cautious conclusion accompanied by the customary appeal for more research. In any event, if one's research goal is not to compare absolute happiness levels but instead to investigate relationships with other factors, cross-national research requires only metric equivalence of data, not scalar equivalence.

The predominance of survey data in happiness studies inevitably raises questions of validity. Addressing those questions in abstract and general ways is probably not a productive exercise; data are not inherently good or bad in themselves. The relevant issue is whether particular data are useful for addressing particular research questions. Even so, there is an extensive methodological literature assessing the general validity of survey data on happiness, finding for example that self-reported happiness corresponds to predicted results of MRI brain scans (Davidson 1992). There are also other forms of data on happiness, including "experience sampling" (e.g. Csikszentmihalyi and Hunter 2003), where research participants are asked to record their happiness levels (and activities) numerous times a day, prompted at random times by a pager; advantages over standard survey approaches include avoidance of distortions rooted in delayed or extended recall. A variant is the "Day Reconstruction Method", which asks participants to construct a diary of activities and emotions for the preceding day, a less expensive method that also causes less disruption to normal daily life (Kahneman et al. 2004). Diary methods can also give us information about variation in individual experience over time (Gershuny 2011). 
Again, many studies on happiness use single-item global self-report measures from surveys, with analysis consisting of cross-sectional regression models, and this approach comes with well-known limitations, particularly for addressing questions of causality. At a minimum, a better form of quantitative analysis uses panel data, to control for unobserved characteristics ("personality" is clearly important) and to address issues of selection and causal direction (cf. Diener et al. 1999).

Qualitative research on happiness is less common (which again could be a reason for sociologists to engage with and contribute to the field). One possible reason is the notion that gaining data on people's perceptions about determinants of happiness might not be a reliable way to learn what actually leads to happiness (see below, on "mistakes"); on the other hand, identifying and exploring discrepancies of this sort would likely be an interesting exercise. Another key question, for which qualitative research is arguably more appropriate, is how people understand and define happiness. Delle Fave et al. (2011) found, via openended questionnaires, that respondents viewed happiness primarily in terms of inner balance and harmony, a dimension that does not commonly find expression in more conventional happiness research (cf. Lu and Shih 1997). Some qualitative research in sociology, while not identifying with happiness studies nor specifying happiness as a topic of investigation, nonetheless includes attention to subjective/affective experience in ways that show complementarity to happiness studies: Furlong and Cartmel (2007), for example, describe the "subjective discomfort" that can accompany young people's experience of increased risk. The example raises a more general question of what is to count as "happiness research". 


\section{What Determines Happiness?}

Quite a number of the pioneers in happiness research are economists, and a core concern of the field is the relationship between happiness, income and economic growth. A touchstone of the literature is the "Easterlin paradox": those with higher incomes are happier than those with lower incomes, but an increase in one's income generally does not lead to an increase in happiness (Easterlin 1973, 1974). On this basis, Easterlin asserts that economic growth contributes nothing to happiness, at least in countries that are already relatively wealthy (2001). This conclusion has been challenged via a different reading of time-series data by Stevenson and Wolfers (2008), with a rebuttal by Easterlin et al. (2010) that includes the assertion that even for developing countries growth might not matter for happiness. A different line of critique emphasizes the need to consider happiness in relation to economic issues beyond income, exploring one's "material situation" more broadly (Christoph 2010), with a significant role for wealth in particular (Headey et al. 2008).

Several basic psychological processes help explain why rising incomes do not generally bring increased happiness. One is the notion that we adapt to the higher level and do not experience lasting subjective benefit - neither from the income itself nor from most of the purchases we make with it (Frederick and Loewenstein, 1999; cf. Scitovsky, 1992). A related issue is aspirations: a higher income might lead to greater happiness if it matched our aspirations for income, but a higher income is typically followed by raised aspirations, for further increases; the gap doesn't close, and our happiness does not change (Easterlin, 2001; Stutzer, 2003). A third process is social comparisons, reflecting the fact that income is in part a positional good: it matters not only in enabling consumption but as a marker of status (this 
is a key reason why in a cross-sectional analysis high-earners are happier than low-earners). If one's income rises in line with the increases of others, then one's ranking remains unchanged, with corresponding implications for happiness (Boyce et al. 2010). Even upward mobility does not guarantee greater happiness: an increase in position leads many people to compare themselves to an even higher reference group, instead of gaining satisfaction from advance relative to a stable reference group (Clark et al. 2008). Happiness researchers often conclude that many people have exaggerated expectations about the value of income for happiness (e.g. Kahneman et al. 2006) and that a materialist orientation is associated with lower happiness (e.g. Frank 1999). ${ }^{1}$

Even the cross-sectional association between income and happiness is weak, relative to associations with other factors (Ball and Chernova 2008). Other factors, some of which are clearly more influential than income, include health, employment (i.e., avoidance of unemployment), marriage (and other forms of stable intimate partnership), religiosity and sociability. As with income, a cross-sectional analysis can produce findings at variance with those resulting from a longitudinal analysis (thus a "paradox"). People living with an intimate partner are happier than those who are single - but a brief "bump" in happiness in the early stages of a relationship is often followed by a decline, perhaps to one's pre-relationship level (Helliwell 2003). However, there is substantial variation among individuals, and for some marriage does lead to a lasting increase in happiness (Lucas et al. 2003). A more persistent negative effect follows from unemployment (e.g. Clark and Oswald 1994, Lucas et al. 2004). Religion matters, in part as a venue for sociability - though it is beneficial in these terms only for those with a strong religious identity (Lim and Putnam 2010). Even so, the effect of 
individual religiosity is moderated by social context: salience of individual religious belief is positively associated with happiness only in countries where aggregate levels of religiosity are higher (Eichhorn 2011). Some researchers (e.g. Brickman and Campbell 1971, Lykken and Tellegan 1996) embraced the notion that individuals have a "set point" of happiness (a.k.a. the "hedonic treadmill") and can do little or nothing to alter a level determined primarily by genes - but this idea seems greatly exaggerated, in light of the significant variation in adaptation to changes in circumstances (Diener et al. 2006, Headey et al. 2010; but see Schnittker 2008 in contrast).

Few key demographic factors make unambiguous independent contributions to happiness models (i.e., controlling for other variables). In bivariate analyses, women often report slightly greater happiness than men - but that difference often disappears in more complex analyses, depending on what control variables are included (Dolan et al. 2008). Age is typically significant, with many researchers finding a U-shaped relationship indicating declining happiness in early adulthood, followed by an increase after middle age; this age (stage in life) effect is robust even when disentangled from period and cohort effects (Yang 2008). Brockmann (2010) finds a "cubic" pattern in which happiness declines again in old age, particularly among women (again controlling for period and cohort effects). It is even more difficult to defend generalizations about race/ethnicity, given different patterns in different countries. Blacks in the US are less happy than whites, a disparity that has decreased in recent decades even while it remains substantial; the difference is (only) partly mediated by other variables (Yang 2008). A clearer finding emerges in relation to immigrants, who are generally less happy than natives (Safi 2010; Bartram 2011); perhaps economic migrants have 
unrealistic expectations about life in wealthy countries, though it is also possible that they experienced below-average happiness prior to migration as well (a point that recalls the desirability of longitudinal analysis to control for selection and unobservable characteristics).

Many studies consider "determinants of happiness" only at the level of individuals, gauging associations with individual characteristics or conditions. In many instances the analyses produce results that amount to sweeping generalizations applying to all individuals in a national (or even global) population. This feature results from use of standard regression models, where the coefficients for different variables describe average associations or effects (a one-unit increase in religiosity, for example, increases happiness by "b" units - i.e., for everyone). A more sophisticated approach recognizes that some variables might have different effects on different types of people. Social capital and civic engagement, for example, are typically found to have a positive association with happiness, but a moderate average effect can be decomposed into a strong positive association for men and childless women and no association at all for mothers (Kroll 2011). The possibility of "slope heterogeneity" of this sort can be investigated with no great difficulty via use of interaction terms.

Another approach, particularly important from a sociological point of view, takes account of social and institutional context, via aggregate-level comparisons. Helliwell (2003) finds several such factors to be particularly significant. One is the extent to which people participate in voluntary and social organizations: on top of the benefits to individuals who participate themselves, memberships have spill-over effects, benefitting others as well (cf. Veenhoven 2004). Another is the quality of a country's governance (cf. Frey and Stutzer 
2002), which is important for effective provision of services and for individuals' confidence about their future. Helliwell finds that country income is not significant once these other country-level factors are accounted for: living in a high-income country appears to matter not in its own right but in the way it facilitates other benefits such as good governance, dense social networks, and good health provision. Income can be treated as a contextual factor operating at sub-national levels as well: Firebaugh and Schroeder (2009) find that individuals are happier when they live in richer neighbourhoods (which have more/better amenities), particularly when those neighbourhoods are located in poor counties (thus facilitating favourable downward comparisons). Context can also affect the association between individual factors and happiness, as indicated in discussions above of religiosity and materialism.

Several features of a country's economic context matter for happiness (Frey 2008), though effects are typically small (Yang 2008). High unemployment reduces happiness even of people with jobs, as they become more fearful of losing them (Di Tella et al. 2003). On the other hand, when unemployment rates are high, those who are unemployed feel less alone and losing one's job seems less like a consequence of personal failure (Clark 2003), though more recent research fails to confirm the notion that being unemployed matters less when unemployment is more common (Pittau et al. 2010). High inflation leads to lower happiness but to a lesser extent than a high unemployment rate, which suggests that the "misery index" (combining unemployment and inflation rates, with equal weighting) gives disproportionate weight to inflation as a factor affecting happiness (Di Tella et al. 2001). High economic inequality is associated with lower happiness - particularly in Europe, less so in the USA 
(Alesina et al. 2004). Economic growth as a contextual factor might operate in counterintuitive ways: Deaton (2008) and Lora and Chaparro (2009) find that a higher growth rate predicts lower happiness when per-capita GDP levels are controlled, suggesting that growth (in addition to giving us "more") brings dislocations that some find uncomfortable (Graham 2009).

Another important contextual factor is culture. Uchida et al. (2004), drawing implications from empirical research by others, suggest that differences in culture have implications for the meanings people ascribe to happiness as well as for motivations and determinants. They work with a very broad distinction between individualist EuropeanAmericans and collectivist East Asians; in the former, happiness is defined in terms of personal achievement and is strongly predicted by self-esteem, while in the latter happiness is more a matter of interpersonal connectedness and the "realization of social harmony" (cf. Kitayama and Markus 2000). They recognize that these regions contain significant internal variation as well, and there is clearly much more that could be done to understand the relationship between culture and happiness.

The presentation in this section so far addresses a question ("what determines happiness?") that might seem appropriately scientific and even reassuringly disinterested. This orientation is probably useful to researchers who seek to dissociate their work from the writings of self-help authors, but ultimately a disinterested orientation (e.g. seeking merely to "explain variation") is likely to be dissatisfying, at odds with motivations for studying happiness. Some contributors are quite willing to frame their work in relation to its public policy implications. Layard (2005), for example, believes that a negative association between 
inequality and happiness warrants the adoption of more progressive taxation regimes. Bartolini (2007) suggests that the Easterlin paradox implies that we should use productivity increases to reduce working hours rather than to raise consumption (cf. Keynes 1972). Many assertions of this sort might be judged to have an insufficient empirical foundation (Dolan et al. 2008), raising the prospect of unintended consequences; some contributions in this mode carry an impression of thinly-veiled politics (e.g. Bok 2010). On the other hand, the topic is unavoidably political and the desire to derive policy implications is by no means a misguided one (Diener et al. 2009).

Individuals seeking to gain insight from happiness research for their own happiness would likely encounter messages perhaps best described as mixed. A core theme emerging over the last decade is the notion that mistaken choices are often unavoidable (Scitovsky 1992, Gilbert 2006, Haybron 2008). We make choices on the basis of our current preferences and understandings, and implicit predictions that our future selves will benefit from the choices of our current selves are often simply inaccurate. We are particularly inclined to undervalue activities and goods with intrinsic attributes (e.g. time with family and friends) and to overvalue activities and goods with extrinsic attributes (Frey 2008). What's worse, there are limits on the extent to which we can learn from past mistakes (Gilbert 2006). (These claims follow closely from a key characteristic of happiness research - the rejection of "revealed preferences", an axiom of conventional neo-classical economics holding that our choices lead to "utility".) In addition, sociologists likely would be pessimistic about prospects for effective individual action in the face of a relatively stable context ("structure"). Even so, some writers are more confident: Sheldon and Lyubomirsky (2006) distinguish between two 
broad sets of factors - circumstances (e.g. income, health) and activities (e.g. developing a new habit or way of perceiving the world) - and find that changes in activities lead more reliably to increased happiness than changes in circumstances; they suggest that individuals should give greater emphasis to the former. Research by Frey (2008) implies a more specific recommendation: watch less television.

\section{The Normative Angle}

Is happiness important? That question operates at several different levels. In normative philosophy, there are venerable perspectives that tell us happiness is not important certainly not as important as acting virtuously, doing one's duty, etc. In contrast, the claim that individual well-being is the only important good characterizes a perspective known as welfarism (also a venerable perspective). Since sociologists have no responsibility to be philosophers, there is probably no need to adopt a radical position, asserting that one perspective is right and all the others are wrong. It is surely sufficient to draw on what Sumner describes as a "weak welfarism": individual well-being is by no means the only thing that matters, but "no theory which fails to find a place for well-being ... could possibly tell the whole story about the good" $(1996,195)$.

A similar approach can ground interest in happiness as an important form of wellbeing. Some "objective" forms of well-being are not important in themselves; they matter only insofar as they enable people to be happy. But here as well there is no need to adopt a radical view. Some forms of objective well-being do matter in their own right. Sen (1999) makes that point compellingly in regard to "capabilities": a person who has lost a limb has lost 
something important, even if she is not unhappy about it. A similar conclusion can be drawn about poverty: it impairs people's capabilities. Income matters; it can matter even when it does not affect people's happiness. But happiness is one of the reasons it matters; alternatively, when income doesn't contribute to happiness, then its importance is arguably diminished.

If sociologists wanted to adopt views about the importance of happiness that diverge from what is presented here, then a foray into normative philosophy would open many possibilities. The results of such an engagement would no doubt include achievement of greater clarity as to the appropriate goals of research. As things stand, many sociologists appear to work with a set of assumptions about research and well-being that could fairly be described as vague. A consideration of happiness studies might lead to a more systematic and coherent perspective in which happiness itself plays no important role - a desirable outcome at least for being more systematic and coherent. The view adopted here - that happiness is an important part of well-being - probably accords with our intuitions (cf. Brülde 2010). As such, it ought to find more consistent and deliberate expression in our research practice as well: well-being matters, happiness is part of what we mean by well-being, and we can profit from studying it directly and from considering it as an implication of research findings on other topics.

\section{Conclusion}

Research on happiness emerged in psychology in part as a reaction against the emphasis on "negative" topics such as mental illness and other forms of dysfunction. A focus on 
dysfunction of various types has long characterised sociology as well, where one finds a central role for concepts such as anomie, alienation, disenchantment, inequality and (more recently) vulnerability. The centrality of these concerns might suggest implications for happiness that sociologists could find very intriguing (Veenhoven 2008). Quite broadly, it suggests that conditions in modern societies are not conducive to happiness: many people (it seems) experience fragile and/or shallow social ties, cannot find meaningful work, are obsessed with material as opposed to spiritual values, are keenly aware of their deprivation (relative to the position of others), and are powerless in the face of relentless social and economic change. What's worse, economic development and globalization lead ever greater numbers of people in the world to live as "we" do, with ostensible consequences for happiness that hardly make development seem like "progress".

Veenhoven (the sociologist with the most extensive engagement with happiness studies) is sceptical of the notion that life in modern societies is not conducive to happiness. Modern wealthy societies are in many ways quite "liveable", and happiness levels are high in absolute terms and in comparison to levels in poorer countries (Veenhoven and Ehrhardt 1995). Many happiness researchers give credence to "comparison theory", which Veenhoven (2008) argues is not well supported by data; people care less about comparisons than is supposed and instead find satisfaction and happiness in having their needs met in an absolute sense. The implication here is that the centrality in sociology of concepts like alienation and relative deprivation might amount to undue emphasis on social dysfunction (though the experiences of those who do not find modern societies to be so "liveable" are surely appropriate for research, even if they do not constitute a majority). This topic might have 
quite significant implications for sociologists' understanding of the discipline and surely deserves much more attention than it has received.

For researchers who do not adopt happiness as the major topic of their research, happiness (and the research about it) is nonetheless relevant and significant at some level, as a form of well-being. At the end of empirical social science journal articles, one often finds a discussion of "policy implications", a suggestion (emerging from the research) that something should be done. The reason "something should be done" can usually be framed in terms of people's well-being (it is, frankly, difficult to imagine a reason that couldn't be framed that way). Unfortunately, these passages in research articles are often underdeveloped to the point that it is difficult to take them seriously. They often appear to be rooted in a commonsense understanding of why certain outcomes would be desirable. While common sense is sometimes a useful guide, one reason to do empirical research is that common sense is evidently insufficient or even misleading for an understanding of how the social world works. Relying on a common-sense understanding of well-being for "policy implications" then presents an unfortunate contrast with the orientation adopted for one's empirical research.

Happiness studies can be a useful way to develop a more systematic orientation to the policy implications of one's research and to the utility (or indeed "impact") of sociological research more generally. One consequence of such an orientation might be greater caution about "policy implications": the "policy" part of that term suggests that one's research implies that governments should do something, and perhaps greater care is required in encouraging extensions of the exercise of state power (though this is not to suggest that such extension is always undesirable). Happiness research itself is sometimes accompanied by discussions of 
what governments might do to increase happiness, as if there were a direct path from findings to policy. While the urge to connect public policy to happiness is laudable at least in the abstract, we might be sceptical (at least given current levels of knowledge) about the notion of a "science of happiness" that could provide the foundation for state-centred programs to increase happiness (Duncan 2010). We might be similarly sceptical about the idea that we can offer meaningful suggestions for government actions more generally, as long as we lack a more systematic understanding of well-being as a foundation for "policy implications". (On the other hand, this conclusion also provides a foundation for critical discussion of what governments already do.)

Again, an engagement with happiness studies might provide a route towards a more systematic engagement with these issues. If well-being (in connection with one's empirical research and its implications) doesn't mean happiness, why not? What does it mean, and why is that alternate meaning preferable? If well-being does mean happiness, then how confident can we really be in believing that our research findings imply a way to do something that might lead to an increase in happiness? After all, "doing something" requires not only a good understanding of the determinants of happiness - it requires good knowledge about how public policy works, including the relationship between research and policy (suggested policy outcomes might not follow directly from adoption of one's "policy implications").

One can study happiness even without a policy orientation; sometimes our goals are limited to insight and understanding (why are some people happier than others?). Even so, these topics are timely, given pressures on academics to demonstrate the public value of their research; whatever concerns one might have about the way "impact" is to be measured in the 
UK, it is surely sensible at some basic level to expect research to be valuable to people apart from other researchers. In practical terms, the UK "National Well-being Project", led by the Office of National Statistics, provides a public focus on the topic that British academics might profitably exploit, even if there is little prospect of (and perhaps no call for) a definitive "final model" of happiness (certainly not one that would justify a grand interventionist state policy designed to increase happiness).

Some scholars (impressionistically: sociologists in particular) appear to prefer a critical mode of engaging with "negative" topics such as alienation and vulnerability; perhaps in researching happiness one would risk an appearance of naïveté, not least for venturing onto ground marked out by self-help writers. The significant (and voluminous) advance of happiness research in other disciplines renders that stance among sociologists unnecessary. Sociologists can contribute to incremental advances and might be well placed to make significant progress on key issues. Happiness studies is a strongly interdisciplinary field, and one might make the case that sociologists would add only to the quantity of researchers, without making a distinctive contribution by virtue of being sociologists. But that notion seems implausible, as it would be for other interdisciplinary topics that sociologists study alongside other social scientists.

Finally, one could distinguish a sociological contribution to happiness studies from a sociological account of happiness (and indeed of happiness studies) and its place in contemporary societies. It is all too easy to assume that if we can learn more about the determinants of happiness it will somehow become easier for individuals or societies to experience greater happiness. To articulate that assumption is to indicate the possibility that 
things might not work out that way, that there might be other kinds of impacts sociologists would want to explore. We might be particularly well placed to investigate changes in how people talk about and act on happiness, analyzing those changes with conventional sociological tools to perceive inequalities, relations of power, etc. that might result from discourses and practices of happiness (cf. Illouz 1997, Ahmed 2010). Happiness research is now firmly on the public agenda, and a sociological investigation of its place in public discourse and policy might reveal a host of unintended consequences.

\section{Notes}

${ }^{1}$ On the other hand, this association is not merely a matter of individual orientations and is affected by one's cultural and economic context: post-material values are more strongly associated with happiness in more affluent countries where post-material values are themselves more widespread (Delhey 2010). 


\section{References}

Ahmed, Sara. 2010. The Promise of Happiness Durham: Duke University Press.

Alesina, Alberto, Rafael Di Tella and Robert MacCulloch. 2004. "Inequality and happiness: are Europeans and Americans different?". Journal of Public Economics 88(9-10): 2009-42.

Ball, Richard and Kateryna Chernova. 2008. "Absolute Income, Relative Income, and Happiness". Social Indicators Research 88(3): 497-529.

Bartolini, Stefano. 2007. Why are people so unhappy? Why do they strive so hard for money? Competing explanations of the broken promises of economic growth. Pp. 337-64, Handbook on the Economics of Happiness, edited by Luigino Bruni \& Pier Luigi Porta. Cheltenham: Edward Elgar.

Bartram, David. 2011. "Economic migration and happiness: comparing immigrants' and natives' happiness gains from income". Social Indicators Research 103(1): 57-76.

Boyce, Christopher J. , Gordon D.A. Brown and Simon C. Moore. 2010. "Money and Happiness: Rank of Income, Not Income, Affects Life Satisfaction". Psychological Science 21(4): 471-75.

Brickman, Philip and Donald Campbell. 1971. Hedonic Relativism and Planning the Good Society. Pp. 287-302, Adaptation-level Theory: A Symposium, edited by Mortimer H. Appley. New York: Academic Press.

Brockmann, Hilke. 2010. "Why are Middle-Aged People so Depressed? Evidence from West Germany". Social Indicators Research 97(1): 23-42.

Brülde, Bengt. 2010. "Happiness, morality, and politics". Journal of Happiness Studies 11(5): 567-83.

Christoph, Bernhard. 2010. "The Relation Between Life Satisfaction and the Material Situation: A Re-Evaluation Using Alternative Measures". Social Indicators Research 98(3): 475-99.

Clark, Andrew E. and Andrew J. Oswald. 1994. "Unhappiness and Unemployment". The Economic Journal 104(424): 648-59.

Clark, Andrew E. 2003. "Unemployment as a Social Norm: Psychological Evidence from Panel Data". Journal of Labor Economics 21(2): 323-51.

Csikszentmihalyi, Mihaly and Jeremy Hunter. 2003. "Happiness in Everyday Life: The Uses of Experience Sampling". Journal of Happiness Studies 4(2): 185-99.

Davidson, Richard J. 1992. "Emotion and Affective Style: Hemispheric Substrates". Psychological Science 3(1): 39-43.

Delhey, Jan. 2010. "From Materialist to Post-Materialist Happiness? National Affluence and Determinants of Life Satisfaction in Cross-National Perspective". Social Indicators Research 97(1): 65-84. 
Delle Fave, Antonella, Ingrid Brdar, Teresa Freire, Dianne Vella-Brodrick and Marié Wissing. 2011. "The Eudaimonic and Hedonic Components of Happiness: Qualitative and Quantitative Findings". Social Indicators Research 100(2): 185-207.

Di Tella, Rafael, Robert MacCulloch and Andrew J. Oswald. 2003. "The Macroeconomics Of Happiness". Review of Economics and Statistics 85(4): 809-27.

Diener, Ed, Richard E. Lucas and Christie Napa Scollon. 2006. "Beyond the Hedonic Treadmill: Revising the Adaptation Theory of Well-Being". American Psychologist 61(4): 305-14.

Diener, Ed, Richard Lucas, Ulrich Schimmack and John Helliwell. 2009. Well-Being for Public Policy Oxford: Oxford University Press.

Diener, Ed, Eunkook M. Suh, Richard E. Lucas and Heidi L. Smith. 1999. "Subjective wellbeing: three decades of progress". Psychological Bulletin 125(2): 276-303.

Dolan, Paul, Tessa Peasgood and Mathew White. 2008. "Do we really know what makes us happy? A review of the economic literature on the factors associated with subjective well-being". Journal of Economic Psychology 29(1): 94-122.

Duncan, Grant. 2010. "Should Happiness-Maximization be the Goal of Government?". Journal of Happiness Studies 11(2): 163-78.

Easterlin, Richard A. 1973. "Does Money Buy Happiness?". Public Interest 30(3-10.

-. 1974. Does economic growth improve the human lot? Pp. 89-125, Nations and Households in Economic Growth: Essays in honor of Moses Abramowitz, edited by Paul A. David \& Melvin W. Reder. New York: Academic Press.

-. 2001. "Income and Happiness: Towards a Unified Theory". The Economic Journal 111(473): 465-84.

Easterlin, Richard A., Laura Angelescu McVey, Malgorzata Switek, Onnicha Sawangfa and Jacqueline Smith Zweig. 2010. "The happiness-income paradox revisited". Proceedings of the National Academy of Sciences.

Eichhorn, Jan. 2011. "Happiness for Believers? Contextualizing the Effects of Religiosity on Life-Satisfaction". European Sociological Review 10.1093/esr/jcr027.

Firebaugh, Glenn and Matthew B. Schroeder. 2009. "Does Your Neighbor's Income Affect Your Happiness?". American Journal of Sociology 115(3): 805-31.

Frank, Robert H. 1999. Luxury fever: money and happiness in an era of excess Princeton: Princeton University Press.

Frederick, Shane and George F. Loewenstein. 1999. Hedonic Adaptation. Pp. 302-29, WellBeing: The Foundations of Hedonic Psychology, edited by Daniel Kahneman, Ed Diener \& Norbert Schwarz. New York: Russell Sage Foundation.

Frey, Bruno S. 2008. Happiness: A Revolution in Economics Cambridge: MIT Press.

Frey, Bruno S. and Alois Stutzer. 2002. Happiness and economics: how the economy and institutions affect human well-being Princeton: Princeton University Press. 
Furlong, Andy and Fred Cartmel. 2007. Young people and social change: new perspectives Maidenhead: McGraw-Hill/Open University Press.

Gershuny, Jonathan. 2011. "Time-Use Surveys and the Measurement of National WellBeing". Office of National Statistics.

Gilbert, Daniel. 2006. Stumbling on Happiness New York: HarperCollins.

Graham, Carol. 2009. Happiness Around the World: The Paradox of Happy Peasants and Miserable Millionaires Oxford: Oxford University Press.

Haybron, Daniel M. 2008. The Pursuit of Unhappiness: The Elusive Psychology of Well-Being Oxford: Oxford University Press.

Headey, Bruce, Ruud Muffels and Mark Wooden. 2008. "Money Does not Buy Happiness: Or Does It? A Reassessment Based on the Combined Effects of Wealth, Income and Consumption". Social Indicators Research 87(1): 65-82.

Helliwell, John F. 2003. "How's life? Combining individual and national variables to explain subjective well-being". Economic Modelling 20(2): 331-60.

Illouz, Eva. 1997. "Who Will Care for the Caretaker's Daughter? Toward a Sociology of Happiness in the Era of Reflexive Modernity". Theory, Culture \& Society 14(4): 31-66.

Kahneman, Daniel, Alan B. Krueger, David A. Schkade, Norbert Schwarz and Arthur A. Stone. 2004. "A Survey Method for Characterizing Daily Life Experience: The Day Reconstruction Method". Science 306(5702): 1776-80.

Kahneman, Daniel, Alan B. Krueger, David Schkade, Norbert Schwarz and Arthur A. Stone. 2006. "Would you be happier if you were richer? A focusing illusion". Science 312(5782): 1908-10.

Keynes, John Maynard. 1972. "Economic Possibilities for Our Grandchildren", in Essays in Persuasion London: Macmillan.

Kitayama, Shinobu and Hazel Rose Markus. 2000. The pursuit of happiness and the realization of sympathy: cultural patterns of self, social relations, and well-being. Pp. 113-61, Culture and subjective well-being, edited by Ed Diener \& Eunkook M. Suh. Cambridge: MIT Press.

Kroll, Christian. 2011. "Different Things Make Different People Happy: Examining Social Capital and Subjective Well-Being by Gender and Parental Status". Social Indicators Research 104(1): 157-77.

Layard, Richard. 2005. Happiness: lessons from a new science New York: Penguin Press.

Lim, Chaeyoon and Robert D. Putnam. 2010. "Religion, Social Networks, and Life Satisfaction". American Sociological Review 75(6): 914-33.

Lora, Eduardo and Juan Camilo Chaparro. 2009. The conflictive relationship between satisfaction and income. Pp. 57-95, Paradox and perception: measuring quality of life in Latin America, edited by Carol Graham \& Eduardo Lora. Washington: Brookings Institution Press. 
Lu, Luo and Jian Bin Shih. 1997. "Sources of happiness: a qualitative approach". The Journal of Social Psychology 137(2): 181-87.

Lucas, Richard E., Andrew E. Clark, Yannis Georgellis and Ed Diener. 2003. "Reexamining Adaptation and the Set Point Model of Happiness: Reactions to Changes in Marital Status". Journal of Personality and Social Psychology 84(3): 527-39.

-. 2004. "Unemployment Alters the Set Point for Life Satisfaction". Psychological Science 15(1): 8-13.

Lykken, David and Auke Tellegen. 1996. "Happiness is a Stochastic Phenomenon". Psychological Science 7(3): 186-89.

Pittau, M. Grazia, Roberto Zelli and Andrew Gelman. 2010. "Economic Disparities and Life Satisfaction in European Regions". Social Indicators Research 96(2): 339-61.

Safi, Mirna. 2010. "Immigrants' Life Satisfaction in Europe: Between Assimilation and Discrimination". European Sociological Review 26(2): 159-71.

Schnittker, Jason. 2008. "Happiness and Success: Genes, Families, and the Psychological Effects of Socioeconomic Position and Social Support". American Journal of Sociology 114(S233-S59).

Scitovsky, Tibor. 1992. The joyless economy: the psychology of human satisfaction Oxford: Oxford University Press.

Sen, Amartya. 1999. Development as Freedom New York: Knopf.

Sheldon, Kennon M. and Sonja Lyubomirsky. 2006. "Achieving Sustainable Gains in Happiness: Change Your Actions, not Your Circumstances". Journal of Happiness Studies 7(1): 55-86.

Stevenson, Betsey and Justin Wolfers. 2008. "Economic Growth and Subjective Well-Being: Reassessing the Easterlin Paradox". IZA Discussion Paper 3654, Institute for the Study of Labor.

Stutzer, Alois. 2003. "The Role of Income Aspirations in Individual Happiness". Journal of Economic Behavior \& Organization 54(1): 89-109.

Sumner, L. W. 1996. Welfare, Happiness and Ethics Oxford: Oxford University Press.

Uchida, Yukiko, Vinai Norasakkunkit and Shinobu Kitayama. 2004. "Cultural constructions of happiness: theory and empirical evidence". Journal of Happiness Studies 5(3): 22339.

Veenhoven, Ruut. 2004. Happiness as an aim in public policy: the greatest happiness principle. Pp. 658-78, Positive Psychology in Practice, edited by Alex Linley \& Stephen Joseph. Hoboken: John Wiley and Sons.

-. 2008. Sociological theories of subjective well-being. Pp. 44-61, The science of subjective well-being: a tribute to Ed Diener, edited by Michael Eid \& Randy Larsen. New York: Guilford Publications. 
Veenhoven, Ruut and J. Ehrhardt. 1995. "The cross-national pattern of happiness: Test of predictions implied in three theories of happiness". Social Indicators Research 34(1): 33-68.

Weber, Max. 1949 [1904]. "'Objectivity' in Social Science and Social Policy", in The Methodology of the Social Sciences New York: The Free Press.

Yang, Yang. 2008. "Social Inequalities in Happiness in the United States, 1972 to 2004: An Age-Period-Cohort Analysis". American Sociological Review 73(2): 204-26. 